\title{
Performance evaluation of AOMdV PROTOCOL BASED ON VARIOUS SCENARIO AND TRAFFIC PATTERNS
}

\author{
P.Periyasamy ${ }^{1}$ and ${ }^{2}$ Dr.E.Karthikeyan \\ ${ }^{1}$ Department of Computer Science and Applications, Sree Saraswathi Thyagaraja \\ College, Pollachi - 642 107, Tamil Nadu, India \\ pereee@yahoo.com \\ ${ }^{2}$ Department of Computer Science, Government Arts College, Udumalpet - 642 126, \\ Tamil Nadu, India \\ e_karthi@yahoo.com
}

\begin{abstract}
A MANET is an interconnection of mobile devices by wireless links, which forms a dynamic topology. Routing protocols play a vital role in transmission of data across the network. The two major classifications of routing protocols are unipath and multipath. In this paper, we have evaluated the performance of a widely used on-demand multipath routing protocol called AOMDV. This protocol has been selected due to its edge over other protocols in various aspects, such as reducing delay, routing load etc. The evaluation of AOMDV protocol is carried out in terms of four scenario patterns such as RWM, RPGM, MGM, and GMM in two different traffic patterns such as CBR and TCP using NS2 and Bonn Motion.
\end{abstract}

\section{KEYWORDS}

MANET, unipath, multipath, AOMDV, RWM, RPGM, MGM, GMM, CBR, TCP, scenario patterns and traffic patterns.

\section{INTRODUCTION}

\subsection{Mobile Ad Hoc Networks}

Mobile Ad hoc NETwork (MANET) is an interconnection of mobile devices by wireless links. It does not need much physical infrastructure such as routers, servers, access points or cables. Each mobile device functions as router as well as node. The most important characteristics of MANET are i) Dynamic topologies ii) Bandwidth-constrained links iii) Energy constrained operation and iv) limited physical security [7]. The various applications of MANETs are: $i$ ) military - communication among soldiers in enemy environments, ii) personal area network printers, PDA, mobile phones, iii) business indoor application - meetings, symposium, demos, iv) civilian outdoor application - taxis, cars, sport stadiums, v) emergency application - emergency rescue operations, police, and earthquakes, and vi) home intelligence devices. 


\subsection{Routing Protocols}

To have communication within the network, a routing protocol is used to discover routes between nodes. The primary goal of such ad-hoc network routing protocol is to establish correct and efficient route between a pair of nodes so that messages may be delivered in a timely manner. Route construction should be done with a minimum of overhead and bandwidth consumption. The two major classifications of MANET routing protocols are unipath and multipath routing protocols.

\subsubsection{Unipath Routing Protocols}

The unipath routing protocols [1] discover a single route between a pair of source and destination. A new route discovery is required in response to every route break which leads high overhead and latency. The two components of unipath routing protocols are $i$ ) Route Discovery: finding a route between a source and destination. ii) Route Maintenance: repairing a broken route or finding a new route in the presence of a route failure. The most commonly used unipath routing protocols are Ad Hoc On-demand Distance Vector (AODV) [6], Dynamic Source Routing (DSR) [6], and Destination Sequenced Distance Vector (DSDV) [6].

\subsubsection{Multipath Routing Protocols}

The multipath routing protocols [1] discover multiple routes between a pair of source and destination in order to have load balancing to satisfy Quality of Service (QoS) requirements. The three main components of multipath routing protocols are $i$ ) Route Discovery: finding multiple nodes disjoint, links disjoint, or non-disjoint routes between a source and destination. ii) Traffic Allocation: Once the route discovery is over, the source node has selected a set of paths to the destination and then begins sending data to the destination along the paths. iii) Path Maintenance: regenerating paths after initial path discovery in order to avoid link/node failures that happened over time and node mobility.

The benefits of the multipath routing protocols are i) Fault tolerance: Being redundant information routed to the destination via alternative paths it reduces the probability of the disruption of communication in case of link failures, ii) Load Balancing: selecting diverse traffic through alternative paths in order to avoid congestion in links, iii) Bandwidth aggregation: Splitting the data into multiple streams and then each of which has routed through a different path to the same destination. Hence the effective bandwidth can be aggregated and iv) Reduced delay: In the unipath routing protocols, the path discovery process needs to be initiated to find a new route in order to avoid a route failure and this leads to high route discovery delay. This delay is minimized in multipath routing protocols by backup routes that have been identified in route discovery process. The most recently used multipath algorithms are Temporarily-Ordered Routing Algorithm (TORA) [3], Split Multipath Routing (SMR) [3], Multipath Dynamic Source Routing (MP-DSR) [1], Ad hoc On-demand Distance Vector-Backup Routing (AODVBR)[3] and Ad Hoc On-Demand Multipath Distance Vector Routing (AOMDV) [3].

The $\boldsymbol{A O M D V}$ protocol is widely used in mobile communication because of its edge over other protocols in various aspects, such as reducing delay, routing load [1,3] etc. It is an on-demand multipath routing protocol - starts a route discovery procedure when needed for MANET. We evaluate its performance in terms of different mobility models such as Random Way point Mobility (RWM), Reference Point Group Mobility (RPGM), Manhattan Grid Mobility (MGM) and Gauss-Markov Mobility (GMM) and also different traffic patterns such as CBR and TCP traffic patterns. To analyze these protocols, traffic patterns and mobility models are essential and are discussed in subsequent sections. 
The rest of this paper is organized as follows: In section 2, the characteristics of traffic patterns are discussed; in section 3 the various mobility models are described; in section 4, the functionality of AOMDV protocol is given; in section 5 the simulation model is discussed; in section 6 the performance metrics are described; in section 6 the experimental results are discussed and finally in section 7 the conclusion is given.

\section{Traffic Patterns}

Traffic Patterns describe how the data is transmitted from source to destination. The two types of traffic patterns employed in MANET are CBR and TCP Traffic patterns.

\subsection{CBR Traffic Pattern}

The qualities of Constant Bit Rate (CBR) traffic pattern [2,14] are $i$ ) unreliable: since it has no connection establishment phase, there is no guarantee that the data is transmitted to the destination, ii) unidirectional: there will be no acknowledgment from destination for confirming the data transmission and iii) predictable: fixed packet size, fixed interval between packets, and fixed stream duration.

\subsection{TCP Traffic pattern}

The qualities of Transmission Control Protocol (TCP) traffic pattern [2,14] are i) reliable: since connection is established prior to transmitting data, there is a guarantee that the data is being transmitted to the destination, ii) bi-directional: every packet that has to be transmitted by the source is acknowledged by the destination, and iii) conformity: there will be flow control of data to avoid overloading the destination and congestion control exists to shape the traffic such that it conforms to the available network capacity [2]. Today more than $95 \%$ of the Internet protocol traffic is carried out through TCP.

\section{Mobility Models}

Mobility models describe the movement pattern of the mobile users, their location; velocity and acceleration $[4,12]$. They play a vital role in determining the performance of a protocol and also differentiated in terms of their spatial and temporal dependencies. i) Spatial dependency is a measure of how two nodes are dependent in their motion. When the two nodes are moving in the same direction, then they have high spatial dependency. ii) Temporal dependency is a measure of how current velocity (magnitude and direction) are related to previous velocity. The two nodes are having the same velocity and direction means that they have high temporal dependency. The commonly used mobility models are RWM, RPGM, MGM and GMM.

\subsection{Random Way point Mobility (RWM)}

RWM [4] model is the commonly used mobility model in which every node randomly chooses a destination and moves towards it from a uniform distribution $\left(\mathbf{0}, \boldsymbol{V}_{\max }\right)$ at any moment of time, where $\boldsymbol{V}_{\max }$ is the maximum allowable velocity for every node. Each node stops for a duration defined by the 'pause time' parameter when it reaches the destination. After the pause time it again chooses a random destination and repeats the whole process until the end of the simulation. 


\subsection{Reference Point Group Mobility (RPGM)}

The military battlefield communication uses RPGM [4] model in which each group has a logical center called Group Leader (GL) for determining the group's motion behavior. Each node in this mobility deviates from its velocity (both magnitude and direction) from that of the leader is calculated as follows:

$$
\begin{aligned}
& \left|V_{M}(t)\right|=\left|V_{L}(t)\right|+\operatorname{random}() * S D R * S_{\text {MAX }} \rightarrow(1) \\
& \left|\boldsymbol{\theta}_{M}(t)\right|=\left|\boldsymbol{\theta}_{L}(t)\right|+\operatorname{random}() * A D R * A_{M A X} \rightarrow \text { (2), }
\end{aligned}
$$

where $\mathrm{V}_{\mathrm{M}}$ and $\mathrm{V}_{\mathrm{L}}$ are the magnitude of member and leader respectively, $\theta_{M}$ and $\theta_{L}$ are direction of member and leader respectively, $\mathrm{S}_{\mathrm{MAX}}$ and $\mathrm{A}_{\mathrm{MAX}}$ are maximum speed and angle respectively, 0 $<$ ADR and SDR < 1, SDR is the Speed Deviation Ratio and ADR is the Angle Deviation Ratio. SDR and ADR employed to control the deviation of the velocity of group members from that of the leader.

\subsection{Manhattan Grid Mobility (MGM)}

MGM [4] models are very useful to emulate the movement pattern of mobile nodes on streets. This is sometimes called Urban Area (UR) model. It forms a number of horizontal and vertical streets like a grid called maps. Each mobile node can be allowed to move along the grid of horizontal and vertical streets on the map. It provides a pervasive computing service between portable devices.

\subsection{Gauss-Markov Mobility (GMM)}

GMM [4] models adopt different levels of randomness through one tuning parameter. In which each mobile node is initialized by a particular speed and direction. The movement updates the speed and direction of each mobile node in a fixed interval of time $\boldsymbol{n}$. The value of speed and direction of the $\boldsymbol{n}^{\text {th }}$ instance is calculated based on the value of speed and direction of the $(\boldsymbol{n}-1)^{t h}$ instance as follows:

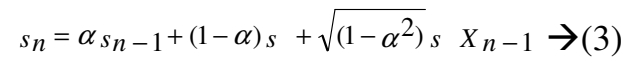

$$
\begin{aligned}
& d_{n}=\alpha d_{n-1}+(1-\alpha) d+\sqrt{\left(1-\alpha^{2}\right)} d \quad X_{n-1} \rightarrow(4),
\end{aligned}
$$

where $s_{n}$ and $d_{n}$ are the new speed and direction of the mobile node at interval $\mathrm{n}, \alpha$ is the tuning parameter to vary the randomness such that $0 \leq \alpha \leq 1, \mathrm{~s}$ and $\mathrm{d}$ are constants of representing speed and direction as $n \rightarrow \alpha$, and $d X_{n-1}$ are random variable derived from Gaussian distribution. The random values are obtained by setting $\alpha=0$ and the linear motion is obtained by setting $\alpha=1$. The intermediate randomness is obtained by varying $\alpha$ between 0 and 1 and the new position of the mobile node is calculated as follows:

$$
\begin{aligned}
& x_{n}=x_{n-1}+s_{n-1} \cos \left(d_{n-1}\right) \rightarrow(5) \\
& y_{n}=y_{n-1}+s_{n-1} \cos \left(d_{n-1}\right) \rightarrow(6),
\end{aligned}
$$

where $\left(x_{n}, y_{n}\right)$ and $\left(x_{n-1}, y_{n-1}\right)$ are the $\mathrm{x}$ and $\mathrm{y}$ coordinates of the mobile node positions at nth and $(n-1)^{\text {th }}$ time intervals respectively. 


\section{Ad hoc On-Demand Multipath Distance Vector Routing (AOMDV)}

The AODV [6] protocol starts a route discovery process through a route request (RREQ) to the destination throughout the network. Once a non-duplicate RREQ is received, the intermediate node records the previous hop and checks for a valid and fresh route entry to the destination. The node sends a route reply (RREP) along with a unique sequence number to the source. On updating the route information, it propagates the route reply and gets additional RREPs if a RREP has either a larger destination sequence number (fresher) or a shorter route found.

To eliminate the occurrence of frequent link failures and route breaks in highly dynamic ad hoc networks, AOMDV has been developed from a unipath path on-demand routing protocol AODV.

The AOMDV [1,3,13] protocol finds multiple paths and this involves two stages which are as follows: i) A route update rule establishes and maintains multiple loop-free paths at each node, and ii) A distributed protocol finds link-disjoint paths.

The AOMDV protocol finds node-disjoint or link-disjoint routes between source and destination. Link failures may occur because of node mobility, node failures, congestion in traffic, packet collisions, and so on. For finding node-disjoint routes, each node does not immediately reject duplicate RREQs. A node-disjoint path is obtained by each RREQ, arriving from different neighbor of the source because nodes cannot broadcast duplicate RREQs. Any two RREQs arriving at an intermediate node through a different neighbor of the source could not have traversed the same node. To get multiple link-disjoint routes, the destination sends RREP to duplicate RREQs regardless of their first hop. For ensuring link-disjointness in the first hop of the RREP, the destination only replies to RREQs arriving through unique neighbors. The RREPs follow the reverse paths, which are node-disjoint and thus link-disjoint after the first hop. Each RREP intersects at an intermediate node and also takes a different reverse path to the source to ensure link-disjointness.

\section{Simulations Model}

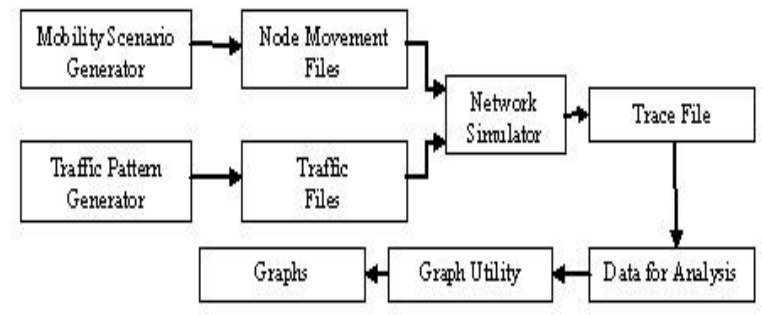

Figure 1. Overview of the simulation model

The performance of AOMDV is evaluated in terms of Scenario and Traffic patterns using NS 2 [5,8] and Bonn Motion [11]. The following Figure 1. illustrates the simulation model [18] and the simulation parameters are described in Table 1 .

The result of simulation is generated as trace files and the awk \& perl scripts are used for report generation. 
International Journal of Computer Science, Engineering and Applications (IJCSEA) Vol.1, No.6, December 2011

Table 1. Simulation Parameters

\begin{tabular}{|l|l|}
\hline \multicolumn{1}{|c|}{ Parameter } & \multicolumn{1}{c|}{ Value } \\
\hline Simulator & NS-2.34 \\
\hline MAC Type & 802.11 \\
\hline Simulation Time & 100 seconds \\
\hline Channel Type & Wireless Channel \\
\hline Routing Protocol & AOMDV \\
\hline Antenna Model & Omni \\
\hline Simulation Area & 1520 m x 1520 m \\
\hline Traffic Type & CBR(udp), TCP(ftp) \\
\hline Data Payload & 512 bytes/packet \\
\hline Network Loads & 4 packets/sec \\
\hline Radio Propagation Model & TwoRayGround \\
\hline Interface Queue Length & 50 \\
\hline Interface Queue Type & DropTail/PriQueue \\
\hline Number of nodes & $25,50,75,100$ \\
\hline Interval & 1000 sec \\
\hline Mobility Model & $\begin{array}{l}\text { Random Way point Mobility, Reference } \\
\text { Point Group Mobility, Manhattan Grid } \\
\text { Mobility, Gauss-Markov Mobility }\end{array}$ \\
\hline
\end{tabular}

\section{Performance Metrics}

Performance Metrics $[9,15,16]$ are quantitative measures that can be used to evaluate any MANET routing protocol. We considered the following six metrics in order to evaluate the multi path on-demand routing protocol AOMDV in terms of four different scenarios such as RWM, RPGM, MGM and GMM and also two different traffic patterns such as CBR and TCP traffic patterns.

\subsection{Packet Delivery Fraction (PDF)}

PDF is the ratio of data packets delivered to the destination to those generated by the sources and is calculated as follows:

$$
\text { Packet Delivery Fraction }=\frac{\text { Numberof Packets Received }}{\text { Number of PacketsSent }} \times 100 .
$$

\subsection{Average Throughput}

Average Throughput [17] is the number of bytes received successfully and is calculated by

$$
\text { Average Throughput }=\frac{\text { Number of bytes received } x 8}{\text { Simulation time } x 1000} \text { kbs. }
$$


International Journal of Computer Science, Engineering and Applications (IJCSEA) Vol.1, No.6, December 2011

\subsection{Routing Overhead}

Routing overhead is the total number of control packets or routing packets generated by routing protocol during simulation and is obtained by

$$
\text { Routing Overhead }=\text { Number of RTR packets. }
$$

\subsection{Normalized Routing Overhead}

Normalized Routing Overhead is the number of routing packets transmitted per data packet towards destination and calculated as follows:

$$
\text { Normalized Routing Overhead }=\frac{\text { Number of Routing Packets }}{\text { Number of Packets Received }} .
$$

\subsection{Average End-to-End Delay (Average e2e delay)}

Average End-to-End [10] delay is the average time of the data packet to be successfully transmitted across a MANET from source to destination. It includes all possible delays such as buffering during the route discovery latency, queuing at the interface queue, retransmission delay at the MAC (Medium Access Control), the propagation and the transfer time. The average e2e delay is computed by,

$$
D=\frac{\sum_{i=1}^{n}\left(R_{i}-S_{i}\right)}{n} m \mathrm{sec},
$$

where $\mathrm{D}$ is the average end-to-end delay, $n$ is the number of data packets successfully transmitted over the MANET, ' $i$ ' is the unique packet identifier, $R i$ is the time at which a packet with unique identifier ' $i$ ' is received and $S_{i}$ is the time at which a packet with unique identifier ' $i$ ' is sent. The Average End-to-End Delay should be less for high performance.

\subsection{Packet Loss}

Packet Loss is the difference between the number of data packets sent and the number of data packets received. It is calculated as follows:

$$
\text { Packet Loss = Number of data packets sent }- \text { Number of data packetsreceived. }
$$

\section{RESULTS AND DISCUSSION}

The performance evaluation of AOMDV protocol is tested in terms of CBR and TCP traffics for different count of nodes namely 25, 50, 75, and 100 under four different scenarios (MANET environments) and the results are as follows: 
International Journal of Computer Science, Engineering and Applications (IJCSEA) Vol.1, No.6, December 2011

\subsection{Packet Delivery Fraction}

Table 2. Packet Delivery Fraction (\%)

\begin{tabular}{|c|c|c|c|c|c|c|c|c|}
\hline & \multicolumn{2}{|c|}{$\begin{array}{c}\text { Random Way point } \\
\text { Mobility }\end{array}$} & \multicolumn{2}{c|}{$\begin{array}{c}\text { Reference Point } \\
\text { Group Mobility }\end{array}$} & \multicolumn{2}{c|}{$\begin{array}{c}\text { Manhattan Grid } \\
\text { Mobility }\end{array}$} & \multicolumn{2}{c|}{$\begin{array}{c}\text { Gauss-Markov } \\
\text { Mobility }\end{array}$} \\
\cline { 2 - 9 } & $\begin{array}{c}\text { No.of } \\
\text { Nodes }\end{array}$ & $\begin{array}{c}\text { TrR } \\
\text { TCP }\end{array}$ & $\begin{array}{c}\text { CBR } \\
\text { Traffic }\end{array}$ & $\begin{array}{c}\text { TCP } \\
\text { Traffic }\end{array}$ & $\begin{array}{c}\text { CBR } \\
\text { Traffic }\end{array}$ & $\begin{array}{c}\text { TCP } \\
\text { Traffic }\end{array}$ & $\begin{array}{c}\text { CBR } \\
\text { Traffic }\end{array}$ & $\begin{array}{c}\text { TCP } \\
\text { Traffic }\end{array}$ \\
\hline 25 & 26.4838 & 98.672 & 92.3698 & 99.1337 & 17.1023 & 99.3025 & 6.42408 & 92.1907 \\
\hline 50 & 91.926 & 98.461 & 56.5843 & 99.281 & 81.4465 & 99.6809 & 24.4066 & 99.356 \\
\hline 75 & 87.9534 & 98.9128 & 99.9552 & 99.2748 & 68.24 & 98.4355 & 87.7569 & 95.9479 \\
\hline 100 & 69.3412 & 97.5973 & 83.0721 & 99.4681 & 51.7682 & 99.1142 & 53.1239 & 98.209 \\
\hline
\end{tabular}

Figure 2.1 and Figure 2.2 shows the delivery rate of the data packets of this protocol is some what significant in CBR traffic in RWM model. However, it is more significant in TCP traffic in RPGM model (More than 99 percent irrespective of number of nodes).

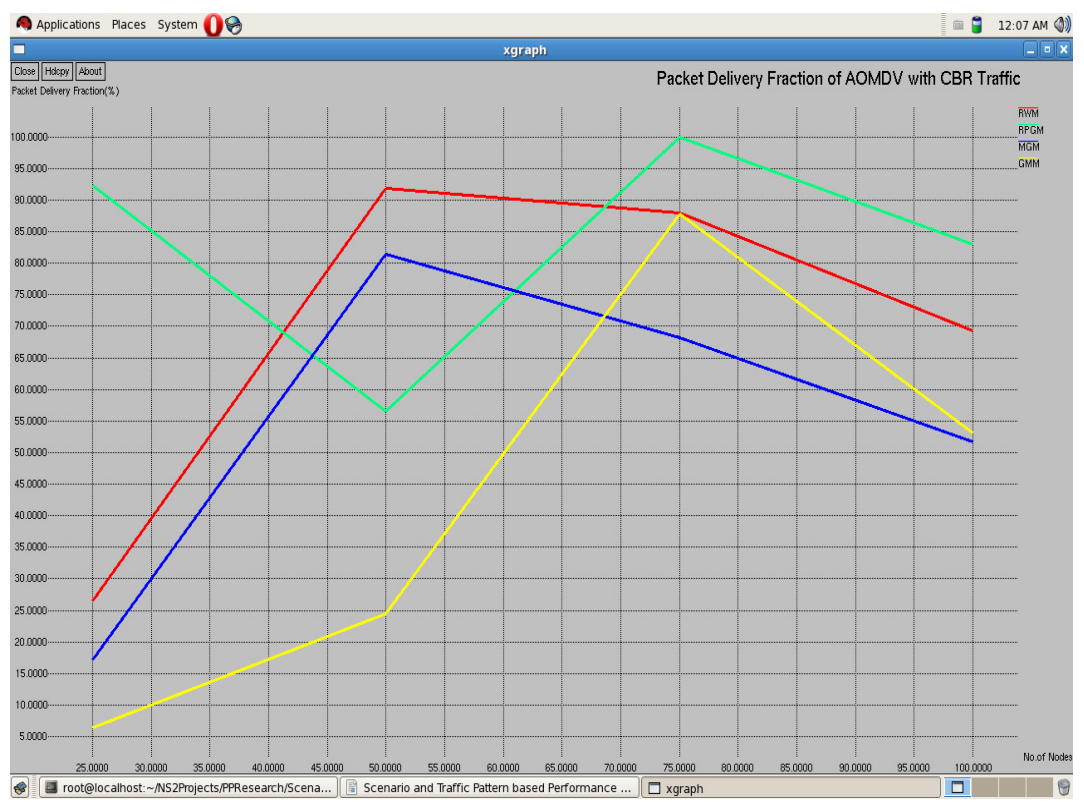

Figure 2.1. Packet Delivery Fraction of AOMDV with CBR Traffic 
International Journal of Computer Science, Engineering and Applications (IJCSEA) Vol.1, No.6, December 2011

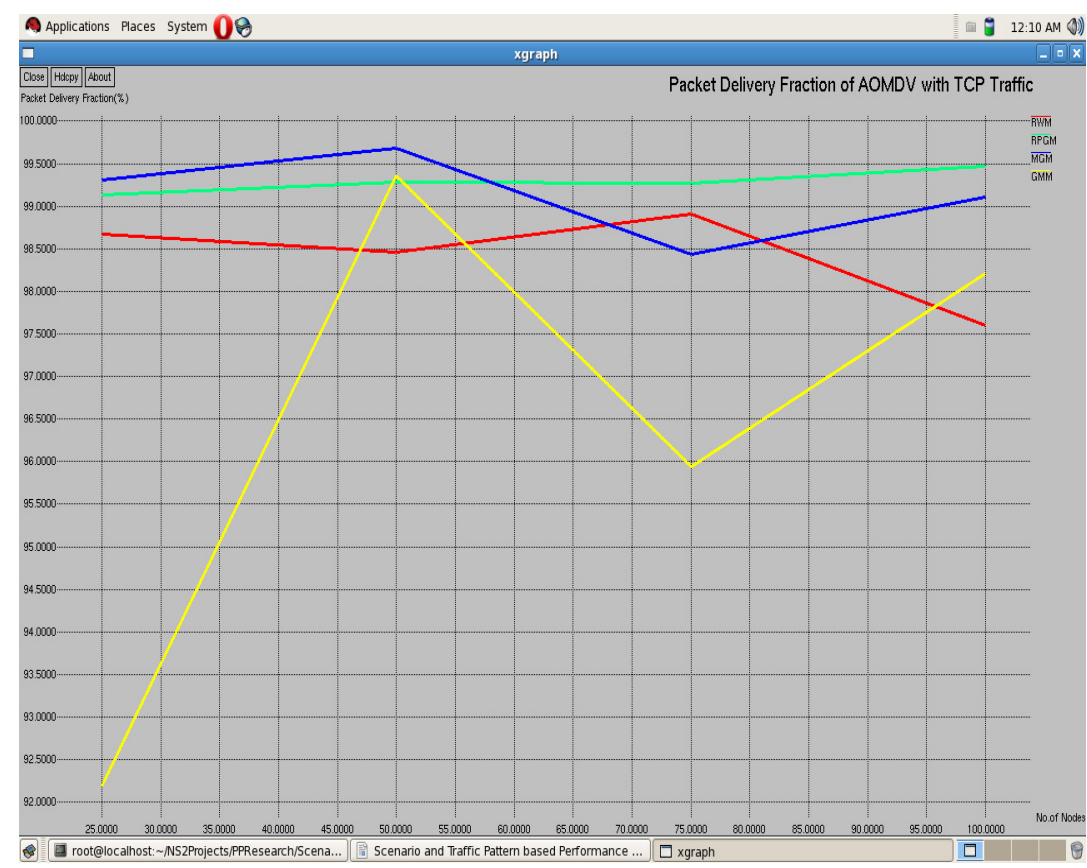

Figure 2.2. Packet Delivery Fraction of AOMDV with TCP Traffic

\subsection{Average End to End Delay}

\begin{tabular}{|r|c|l|c|l|l|l|r|r|}
\hline & \multicolumn{2}{|c|}{$\begin{array}{c}\text { Random Way point } \\
\text { Mobility }\end{array}$} & \multicolumn{2}{c|}{$\begin{array}{c}\text { Reference Point } \\
\text { Group Mobility }\end{array}$} & \multicolumn{2}{c|}{$\begin{array}{c}\text { Manhattan Grid } \\
\text { Mobility }\end{array}$} & \multicolumn{2}{c|}{$\begin{array}{c}\text { Gauss-Markov } \\
\text { Mobility }\end{array}$} \\
\cline { 2 - 9 } $\begin{array}{c}\text { No.of } \\
\text { Nodes }\end{array}$ & $\begin{array}{l}\text { CBR } \\
\text { Traffic }\end{array}$ & $\begin{array}{l}\text { TCP } \\
\text { Traffic }\end{array}$ & $\begin{array}{l}\text { CBR } \\
\text { Traffic }\end{array}$ & $\begin{array}{l}\text { TCP } \\
\text { Traffic }\end{array}$ & $\begin{array}{l}\text { CBR } \\
\text { Traffic }\end{array}$ & $\begin{array}{l}\text { TCP } \\
\text { Traffic }\end{array}$ & $\begin{array}{l}\text { CBR } \\
\text { Traffic }\end{array}$ & $\begin{array}{l}\text { TCP } \\
\text { Traffic }\end{array}$ \\
\hline 25 & 0.689685 & 46.6322 & 12.9071 & 150.799 & 13.453 & 84.74 & 1.43374 & 0 \\
\hline 50 & 35.303 & 102.126 & 2.90924 & 122.038 & 12.4105 & 9.14614 & 0.615091 & 101.84 \\
\hline 75 & 58.8229 & 46.8142 & 45.9368 & 50.1088 & 60.1209 & 1576.36 & 68.8816 & 133.305 \\
\hline 100 & 93.9716 & 72.9806 & 41.2503 & 40.4549 & 565.213 & 91.4236 & 630.539 & 1554.73 \\
\hline
\end{tabular}

Table 3. Average End to End Delay (in ms)

Figure 3.1 and Figure 3.2 shows the end-to-end delay of this protocol is more significant in both CBR and TCP traffics in RPGM model. 
International Journal of Computer Science, Engineering and Applications (IJCSEA) Vol.1, No.6, December 2011

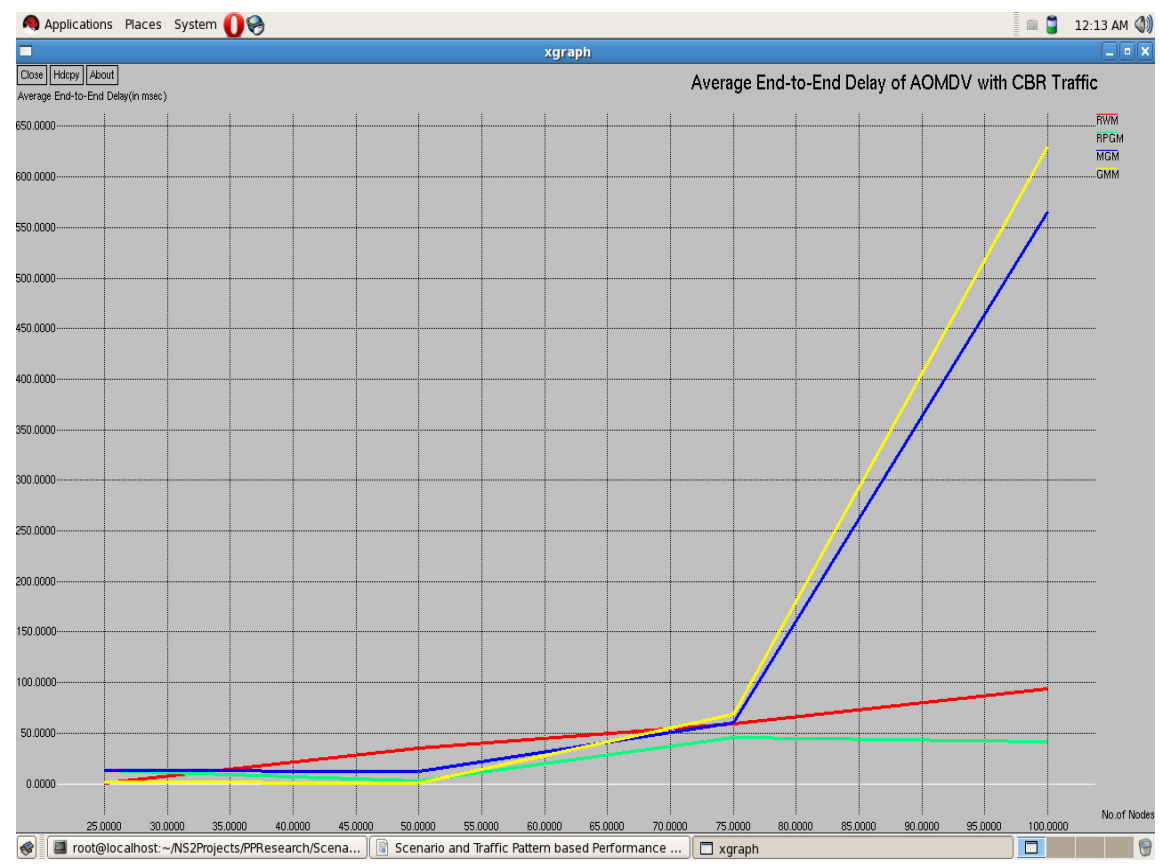

Figure 3.1. Average End-to-End Delay of AOMDV with CBR Traffic

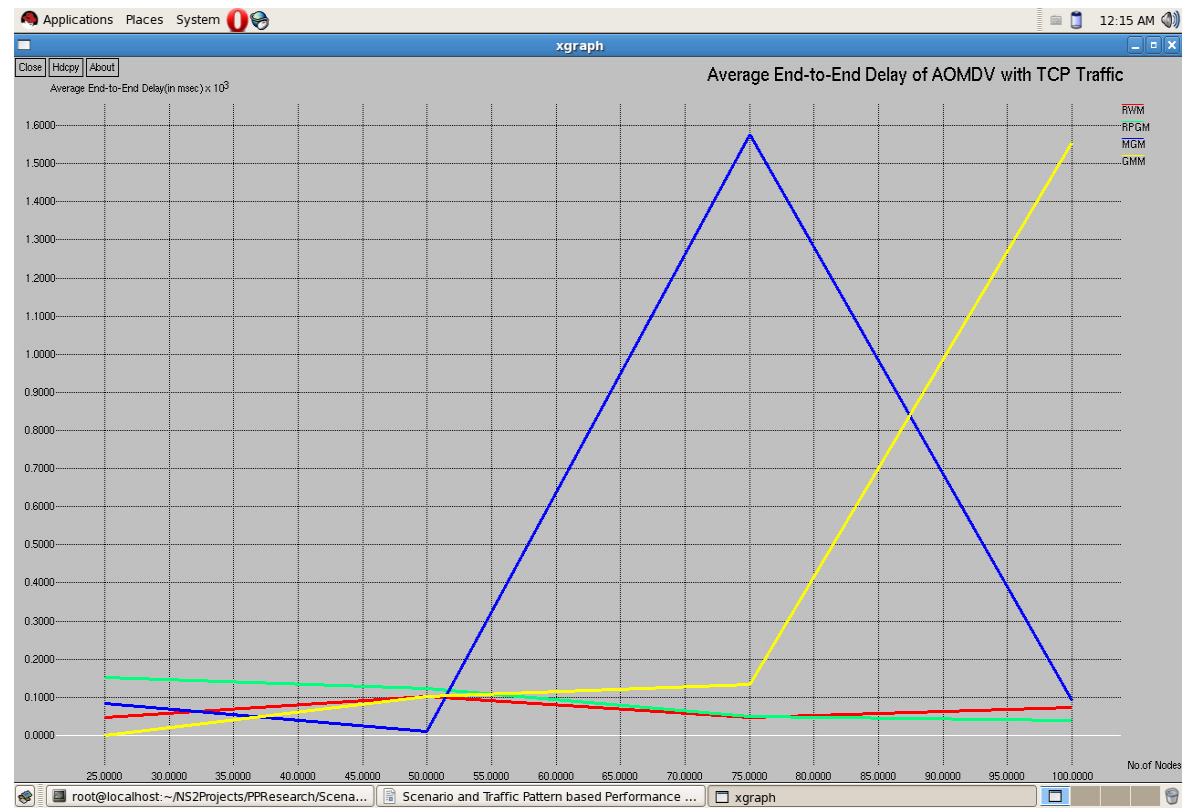

Figure 3.2. Average End-to-End Delay of AOMDV with TCP Traffic 
International Journal of Computer Science, Engineering and Applications (IJCSEA) Vol.1, No.6, December 2011

\subsection{Average Throughput}

Table 4. Throughput (in kbps)

\begin{tabular}{|r|r|l|r|l|r|r|r|r|}
\hline & \multicolumn{2}{|c|}{$\begin{array}{c}\text { Random Way } \\
\text { point Mobility }\end{array}$} & \multicolumn{2}{|c|}{$\begin{array}{l}\text { Reference Point } \\
\text { Group Mobility }\end{array}$} & \multicolumn{2}{|c|}{$\begin{array}{c}\text { Manhattan } \\
\text { Grid Mobility }\end{array}$} & \multicolumn{2}{|c|}{$\begin{array}{l}\text { Gauss-Markov } \\
\text { Mobility }\end{array}$} \\
\cline { 2 - 9 } $\begin{array}{c}\text { No.of } \\
\text { Nodes }\end{array}$ & $\begin{array}{l}\text { CBR } \\
\text { Traffic }\end{array}$ & $\begin{array}{l}\text { TCP } \\
\text { Traffic }\end{array}$ & $\begin{array}{l}\text { CBR } \\
\text { Traffic }\end{array}$ & $\begin{array}{l}\text { TCP } \\
\text { Traffic }\end{array}$ & $\begin{array}{l}\text { CBR } \\
\text { Traffic }\end{array}$ & $\begin{array}{l}\text { TCP } \\
\text { Traffic }\end{array}$ & $\begin{array}{l}\text { CBR } \\
\text { Traffic }\end{array}$ & \multicolumn{1}{l|}{$\begin{array}{l}\text { TCP } \\
\text { Traffic }\end{array}$} \\
\hline 25 & 24.13 & 273.67 & 84.32 & 468.39 & 15.84 & 355.64 & 10.4 & 65.74 \\
\hline 50 & 83.49 & 348.21 & 51.57 & 757.62 & 74.27 & 908.06 & 22.33 & 499.11 \\
\hline 75 & 80.45 & 216.96 & 91.31 & 745.44 & 62.22 & 314.05 & 80.47 & 162.45 \\
\hline 100 & 154.37 & 367.34 & 184.55 & 895.97 & 114.56 & 494.42 & 118.43 & 269.08 \\
\hline
\end{tabular}

Figure 4.1 and Figure 4.2 shows the average throughput of this protocol is more significant in both CBR and TCP traffics in RPGM model. However, it is some what significant in both CBR and TCP traffics in RWM model.

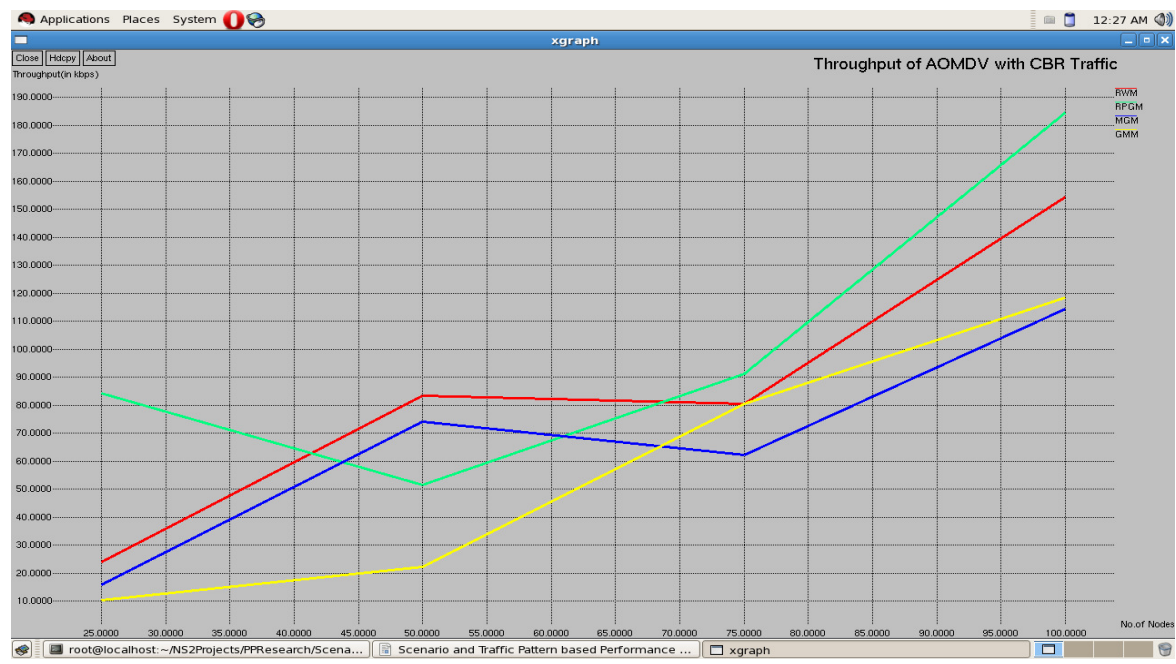

Figure4.1. Throughput of AOMDV with CBR Traffic

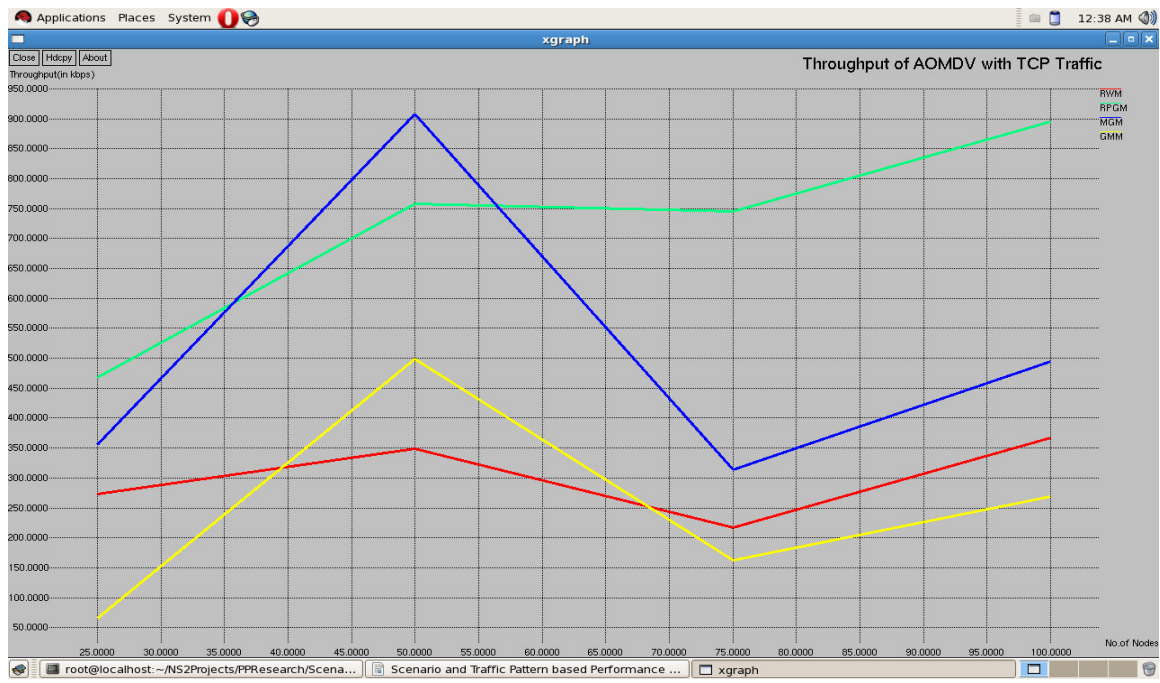

Figure 4.2. Throughput of AOMDV with TCP Traffic 
International Journal of Computer Science, Engineering and Applications (IJCSEA) Vol.1, No.6, December 2011

\subsection{Packet Loss}

Table 5. Packet Loss (in pkts)

\begin{tabular}{|c|c|c|c|c|c|c|c|c|}
\hline \multirow[b]{2}{*}{$\begin{array}{l}\text { No.of } \\
\text { Node } \\
\text { s }\end{array}$} & \multicolumn{2}{|c|}{$\begin{array}{l}\text { Random Way } \\
\text { point Mobility }\end{array}$} & \multicolumn{2}{|c|}{$\begin{array}{l}\text { Reference Point } \\
\text { Group Mobility }\end{array}$} & \multicolumn{2}{|c|}{$\begin{array}{c}\text { Manhattan } \\
\text { Grid Mobility }\end{array}$} & \multicolumn{2}{|c|}{$\begin{array}{c}\text { Gauss-Markov } \\
\text { Mobility }\end{array}$} \\
\hline & $\begin{array}{l}\text { CBR } \\
\text { Traffi } \\
\text { c }\end{array}$ & $\begin{array}{l}\text { TCP } \\
\text { Traffic }\end{array}$ & $\begin{array}{l}\text { CBR } \\
\text { Traffi } \\
\text { c }\end{array}$ & $\begin{array}{l}\text { TCP } \\
\text { Traffic }\end{array}$ & $\begin{array}{l}\text { CBR } \\
\text { Traffi } \\
\text { c }\end{array}$ & $\begin{array}{l}\text { TCP } \\
\text { Traffi } \\
\text { c }\end{array}$ & $\begin{array}{l}\text { CBR } \\
\text { Traffi } \\
\text { c }\end{array}$ & $\begin{array}{l}\text { TCP } \\
\text { Traffic }\end{array}$ \\
\hline 25 & 1635 & 90 & 170 & 100 & 1871 & 61 & 2083 & 77 \\
\hline 50 & 179 & 133 & 966 & 134 & 413 & 71 & 1688 & 79 \\
\hline 75 & 269 & 58 & 1 & 133 & 707 & 122 & 274 & 168 \\
\hline 100 & 1666 & 221 & 918 & 117 & 2605 & 108 & 2551 & 120 \\
\hline
\end{tabular}

Figure 5.1 and Figure 5.2 shows the Packet Loss of this protocol is significant in CBR Traffic in RPGM model and in TCP Traffic in MGM model.

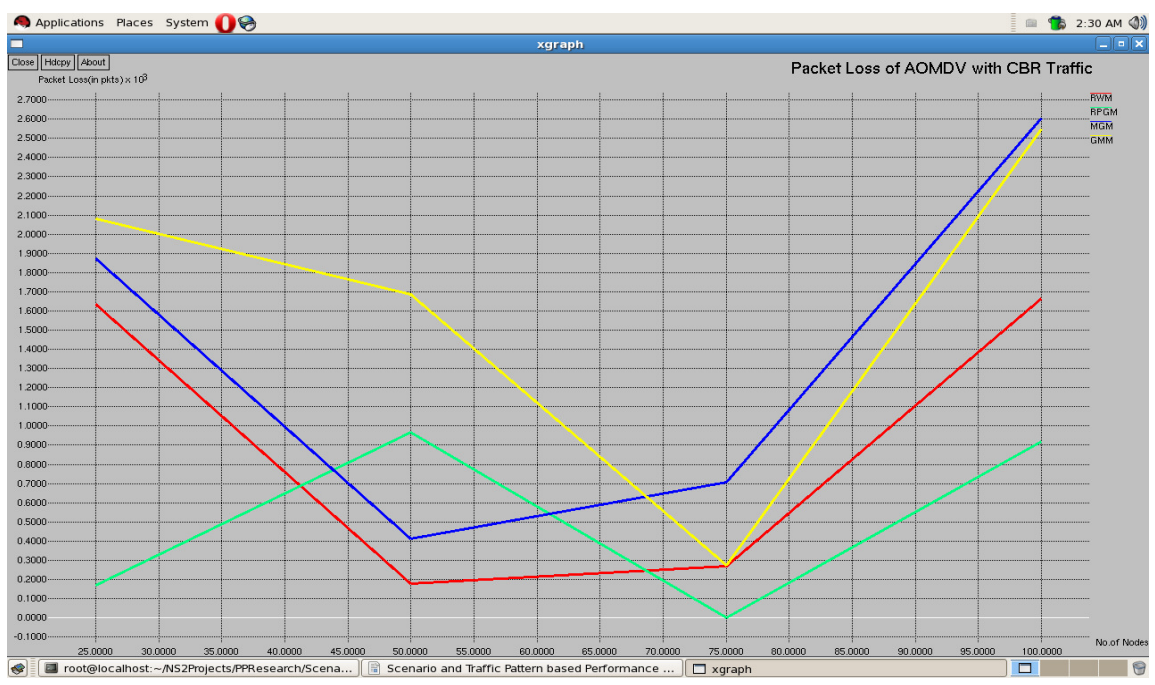

Figure 5.1. Packet Loss of AOMDV with CBR Traffic

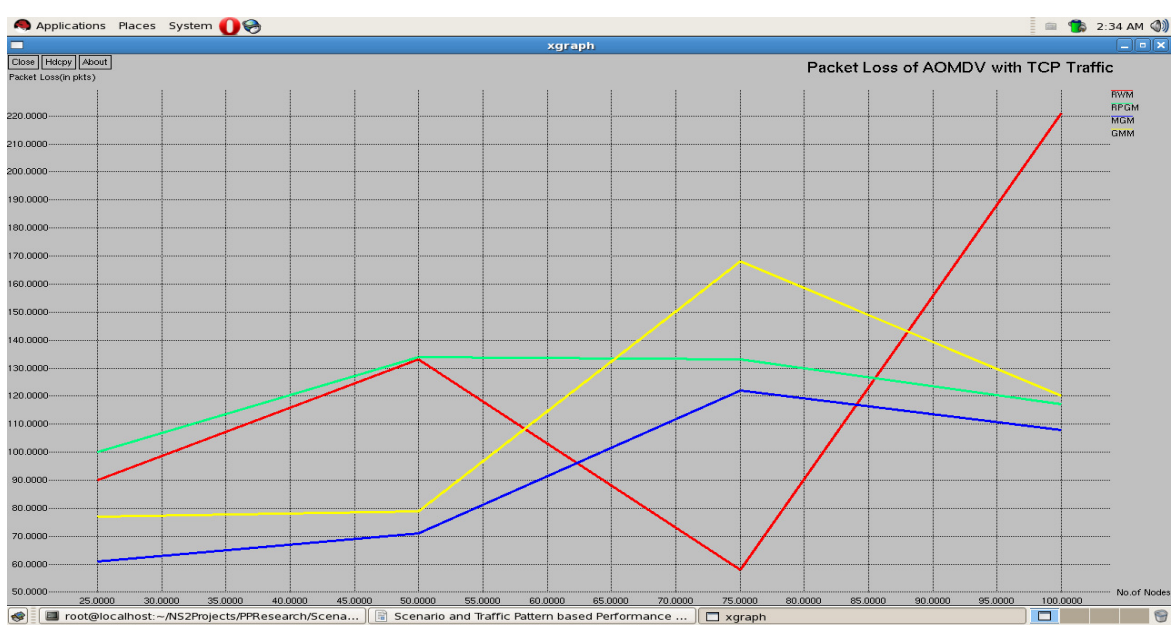

Figure 5.1. Packet Loss of AOMDV with TCP Traffic 
International Journal of Computer Science, Engineering and Applications (IJCSEA) Vol.1, No.6, December 2011

\subsection{Routing Overhead}

Table-6: Routing Overhead (in pkts)

\begin{tabular}{|r|r|l|r|r|r|l|r|r|}
\hline & \multicolumn{2}{|c|}{$\begin{array}{c}\text { Random Way point } \\
\text { Mobility }\end{array}$} & \multicolumn{2}{|c|}{$\begin{array}{l}\text { Reference Point } \\
\text { Group Mobility }\end{array}$} & \multicolumn{2}{|c|}{$\begin{array}{l}\text { Manhattan Grid } \\
\text { Mobility }\end{array}$} & \multicolumn{2}{|c|}{$\begin{array}{c}\text { Gauss-Markov } \\
\text { Mobility }\end{array}$} \\
\cline { 2 - 9 } $\begin{array}{c}\text { No.of } \\
\text { Nodes }\end{array}$ & $\begin{array}{l}\text { CBR } \\
\text { Traffic }\end{array}$ & $\begin{array}{l}\text { TCP } \\
\text { Traffic }\end{array}$ & $\begin{array}{l}\text { CBR } \\
\text { Traffic }\end{array}$ & $\begin{array}{c}\text { TCP } \\
\text { Traffic }\end{array}$ & $\begin{array}{l}\text { CBR } \\
\text { Traffic }\end{array}$ & $\begin{array}{l}\text { TCP } \\
\text { Traffic }\end{array}$ & $\begin{array}{l}\text { CBR } \\
\text { Traffic }\end{array}$ & $\begin{array}{l}\text { TCP } \\
\text { Traffic }\end{array}$ \\
\hline 25 & 1568 & 57 & 152 & 4 & 1757 & 49 & 1953 & 73 \\
\hline 50 & 174 & 36 & 933 & 15 & 410 & 19 & 1627 & 28 \\
\hline 75 & 250 & 49 & 0 & 15 & 680 & 92 & 264 & 120 \\
\hline 100 & 1112 & 176 & 876 & 8 & 2084 & 95 & 1722 & 107 \\
\hline
\end{tabular}

Figure 6.1 and Figure 6.2 shows the Routing Overhead of this protocol is low in both CBR and TCP traffics in RPGM model. However, it is some what high in both CBR and TCP traffics in RWM model.

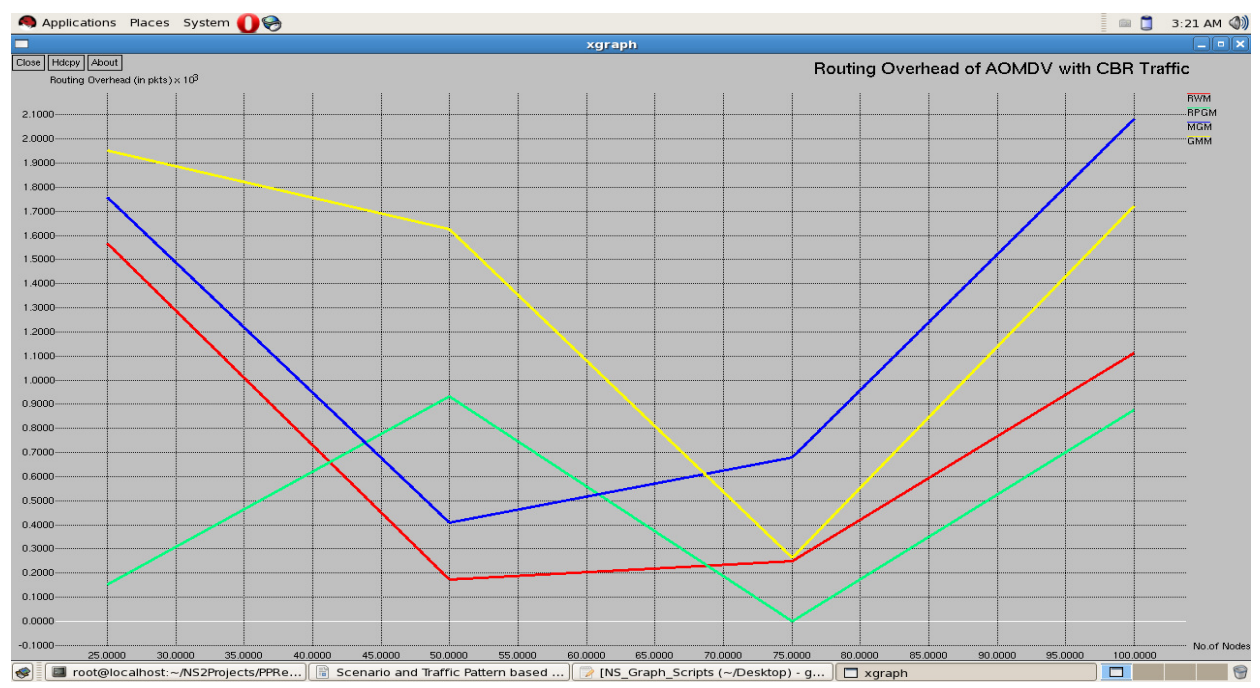

Figure 6.1. Routing Overhead of AOMDV with CBR Traffic

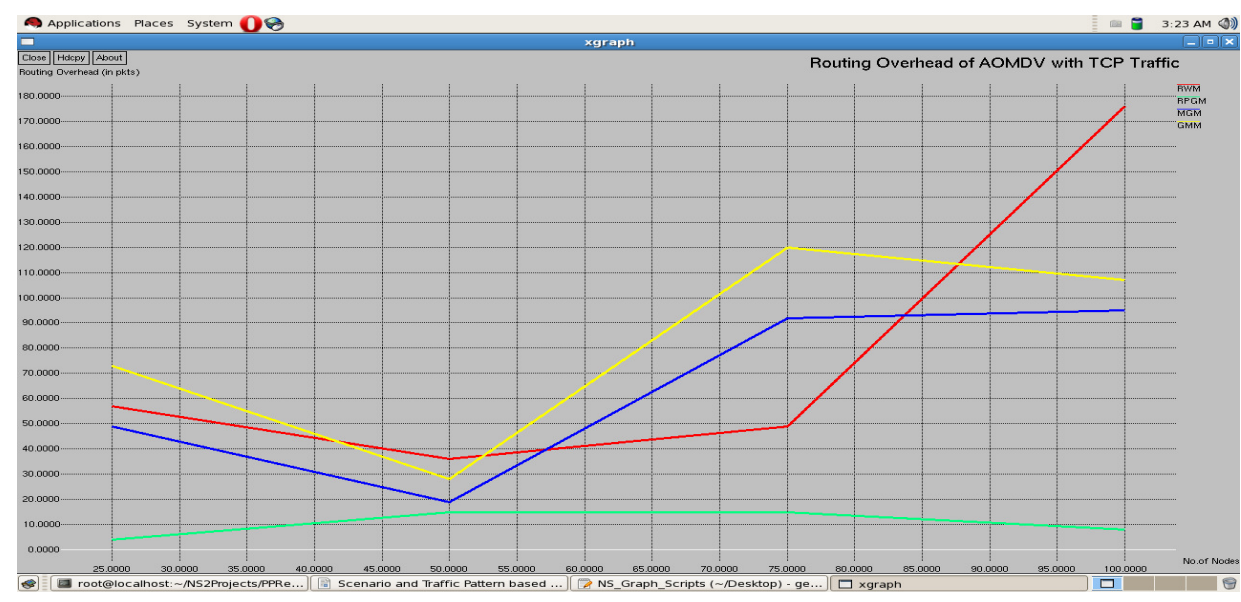

Figure 6.2. Routing Overhead of AOMDV with TCP Traffic 
International Journal of Computer Science, Engineering and Applications (IJCSEA) Vol.1, No.6, December 2011

\subsection{Normalized Routing Overhead}

Table 6. Normalized Routing Overhead

\begin{tabular}{|c|c|c|c|c|c|c|c|c|}
\hline \multirow[b]{2}{*}{$\begin{array}{l}\text { No.of } \\
\text { Nodes }\end{array}$} & \multicolumn{2}{|c|}{$\begin{array}{c}\text { Random Way point } \\
\text { Mobility }\end{array}$} & \multicolumn{2}{|c|}{$\begin{array}{c}\text { Reference Point Group } \\
\text { Mobility }\end{array}$} & \multicolumn{2}{|c|}{$\begin{array}{l}\text { Manhattan Grid } \\
\text { Mobility }\end{array}$} & \multicolumn{2}{|c|}{$\begin{array}{l}\text { Gauss-Markov } \\
\text { Mobility }\end{array}$} \\
\hline & $\begin{array}{l}\text { CBR } \\
\text { Traffic }\end{array}$ & $\begin{array}{l}\text { TCP } \\
\text { Traffic }\end{array}$ & $\begin{array}{l}\text { CBR } \\
\text { Traffic }\end{array}$ & TCP Traffic & $\begin{array}{l}\text { CBR } \\
\text { Traffic }\end{array}$ & TCP Traffic & $\begin{array}{l}\text { CBR } \\
\text { Traffic }\end{array}$ & $\begin{array}{l}\text { TCP } \\
\text { Traffic }\end{array}$ \\
\hline 25 & & & 0.0738581 & & 4.5518 & & 13.6573 & \\
\hline 50 & 0.0853778 & 0042 & 0.741064 & & 0.2261 & 0.00085 & 2.98 & 0.0022973 \\
\hline 75 & 0.127291 & 0.0092856 & 0 & & 0.4476 & & 0.13 & 0.0301659 \\
\hline 100 & 0.295117 & 0.0196057 & 0.194451 & 0.000365614 & 0.745351 & 0.00786164 & 0.595642 & 0.0162614 \\
\hline
\end{tabular}

Figure 7.1 and Figure 7.2 shows the Normalized Routing Overhead of this protocol is low in both CBR and TCP traffics in RPGM model. However, it is some what high in both CBR and TCP traffics in RWM model.

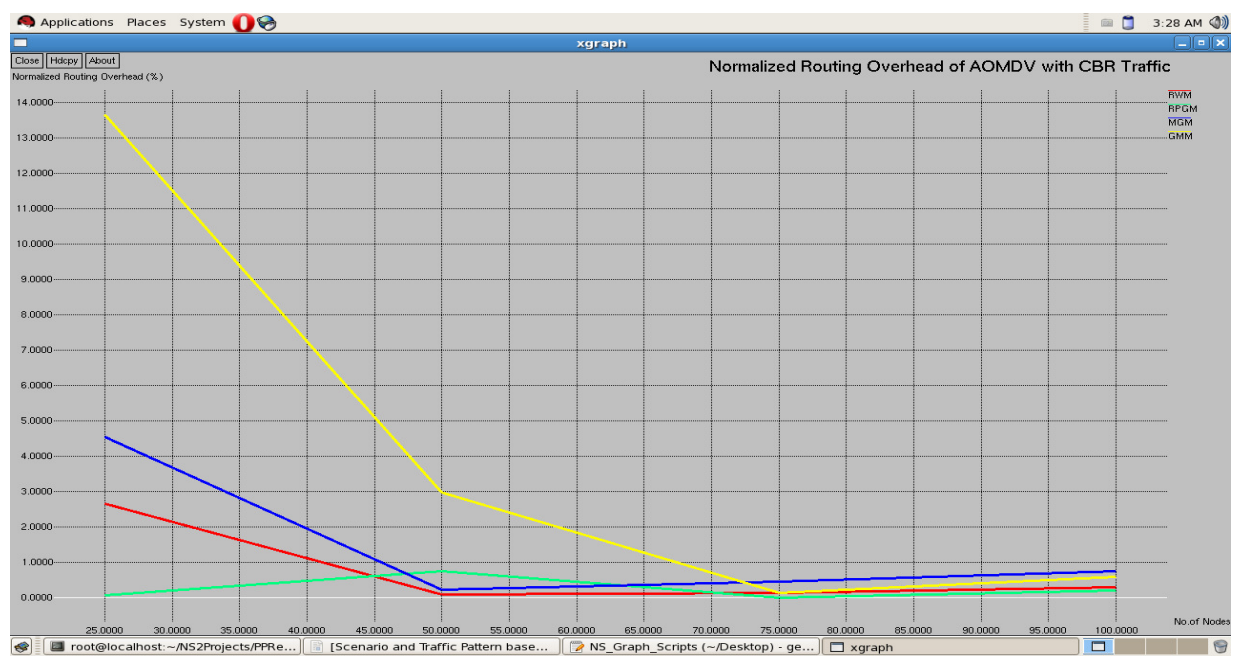

Figure 7.1. Normalized Routing Overhead of AOMDV with CBR Traffic

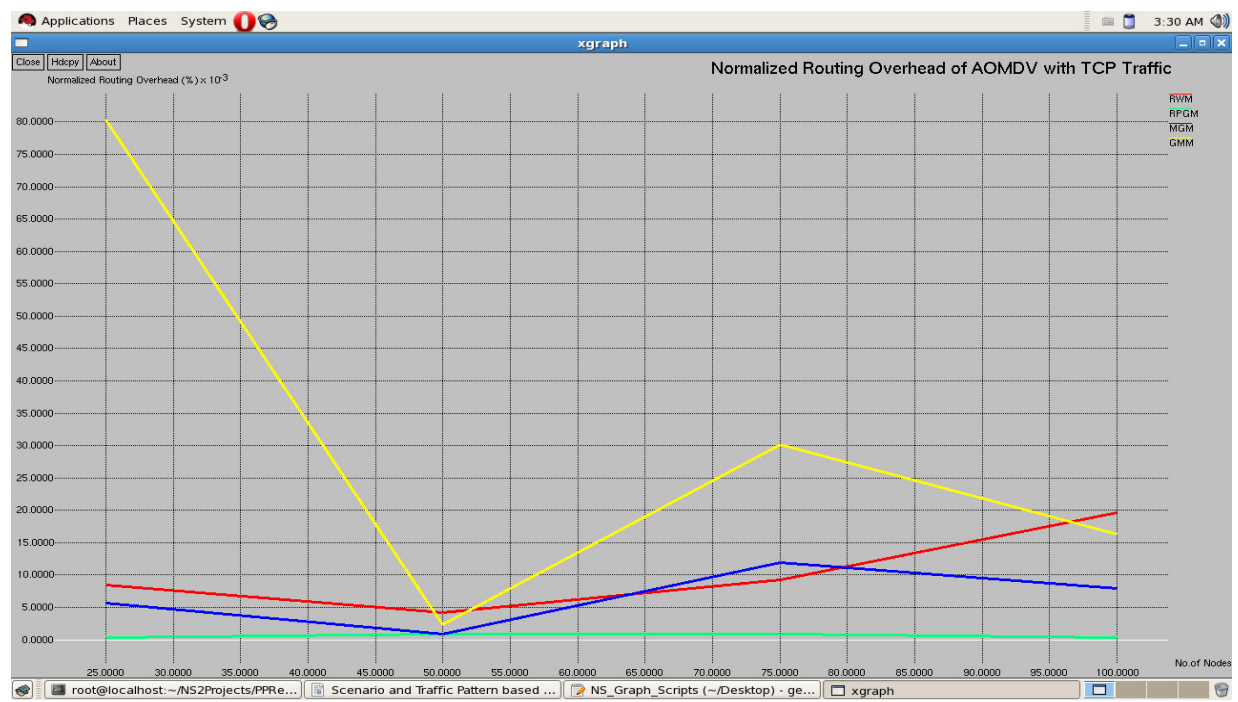

Figure 7.2. Normalized Routing Overhead of AOMDV with TCP Traffic 
International Journal of Computer Science, Engineering and Applications (IJCSEA) Vol.1, No.6, December 2011

\section{CONCLUSION}

In both CBR traffic and TCP traffic, the AOMDV gives significant performance in RPGM model. Due to randomness in mobility among mobile nodes, the RWM model is widely used in MANETs. We have selected AOMDV for evaluation due to its edge over other protocols.

\section{REFERENCES}

[1] V.C.Patil, Rajashree, V.Biradar, R.R. Mudholkar, S.R.Sawant, "On-Demand Multipath Routing Protocols for Mobile Ad Hoc Networks Issues and Comparison", International Journal of Wireless Communication and Simulation, 2010,Vol. 2(1), pp. 21-38.

[2] Thomas Clausen, Philippe Jacquet, Laurent Viennot, "Comparative study of CBR and TCP Performance of MANET routing protocols", Technical report, Project HiPERCOM, INRIA Rocquencourt, 2002.

[3] R.L.Lagendijik, J.F.C.M.de Jongh, "Multipath Routing in Mobile Ad Hoc Networks", Traineeship Report, Version 1.2, TU-Delft/TNO, 2003.

[4] C.P.Agrawal, O.P.Vyas, M.K.Tiwari, "Evaluation of varying mobility models \& network loads on DSDV protocol of MANETs", International Journal of Computer Science and Engineering, 2009, Vol. 1(2), pp. 40-46.

[5] The Network Simulator ns-allinone-2.34, http://www.isi.edu/nsnam/ns/

[6] Elizabeth M. Royer, C-K Toh, "A Review of Current Routing Protocols for Ad-Hoc Mobile Wireless Networks”, IEEE Personal Communications, April 1999, pp.46-55.

[7] Sapna S. Kaushik, P.R.Deshmukh, "Comparison of effectiveness of AODV, DSDV and DSR Routing Protocols in Mobile Ad hoc Networks", International Journal of Information Technology and Knowledge Management, 2009, Vol. 2(2), pp.499-502.

[8] Kevin Fall, K. Varadhan, "The ns Manual", University of Southern California, Information Sciences Institute (ISI), http://www.isi.edu/nsnam/ns/ns-documentation.html.

[9] Harminder S. Bindra1, Sunil K. Maakar, A. L. Sangal , "Performance Evaluation of Two Reactive Routing Protocols of MANET using Group Mobility Model", IJCSI International Journal of Computer Science Issues, 2010,Vol. 7(10), pp.38-43.

[10] Anuj K. Gupta, Harsh Sadawarti, Anil K. Verma, "Performance analysis of AODV, DSR \& TORA Routing Protocols", IACSIT International Journal of Engineering and Technology, 2010, Vol.2 (2), pp.226-231.

[11] The Bonn Motion, http://bonnmotion.cs.uni-bonn.de/

[12] Mohd Izuan Mohd Saad, Zuriati Ahmad Zukarnain, "Performance Analysis of Random-based Mobility Models in MANET Protocols”, European Journal of Scientific Research, 2009, Vol. 32(4), pp. 444-454.

[13] Sujata V.Mallapur, Sujata .Terdal, Enhanced, "Ad-Hoc on Demand Multipath Distance Vector Routing Potocol (EAOMDV)", International Journal of Computer Science and Information Security, 2010,Vol. 7 (3), pp.166-170.

[14] Vikas Singla, Parveen Kakkar,"Traffic Pattern based performance comparison of Reactive and Proactive protocols of Mobile Ad-hoc Networks", International Journal of Computer Applications, 2010,Vol. 5(10), pp.16-20. 
International Journal of Computer Science, Engineering and Applications (IJCSEA) Vol.1, No.6, December 2011

[15] S. R. Das, R. Castaeda, J. Yan, "Simulation-based performance evaluation of routing protocols for mobile ad hoc networks", Mobile Networks and Applications, 2000,Vol. 5, pp.179-189.

[16] S.Corson, J.Macker, "Routing Protocol Performance Issues and Evaluation Considerations", RFC2501, IETF Networking Group, January 1999.

[17] A.Valarmathi, RM.Chandrasekaran, "Congestion Aware and Adaptive Dynamic Source Routing Algorithm with Load Balancing in MANETs", International Journal of Computer Applications, 2010, Vol. 8(5), pp.1-4.

[18] NS-2 with Wireless and Mobility Extensions, http://www.monarch .cs.cmu.edu. 